\title{
The effect of conspecific removal on behavioral and physiological responses of dairy cattle
}

\author{
Jessica K. Walker, ${ }^{+}{ }^{1}$ David R. Arney, $\ddagger$ Natalie K. Waran,§ lan G. Handel,\# and Clive J. C. Phillips* \\ ${ }^{*}$ Centre for Animal Welfare and Ethics, School of Veterinary Sciences, University of Queensland 4343, Australia \\ †The Animal Welfare and Biodiversity Research Group, Department of Natural Sciences, Unitec, Private Bag 92025, Auckland 1025, \\ New Zealand \\ łInstitute of Veterinary Medicine and Animal Sciences, Estonian University of Life Sciences. Kreutzwaldi 46, 51006 Tartu, Estonia \\ §Jeanne Marchig International Centre for Animal Welfare Education, Royal (Dick) School of Veterinary Studies, the University of Edinburgh, \\ Easter Bush, Roslin, EH25 9RG, UK \\ \#The Royal (Dick) School of Veterinary Studies, The University of Edinburgh, Easter Bush Campus, Midlothian EH25 9RG, UK
}

\section{ABSTRACT}

Adverse social and welfare implications of mixing dairy cows or separating calves from their mothers have been documented previously. Here we investigated the behavioral and physiological responses of individuals remaining after conspecifics were removed. We conducted a series of 4 experiments incorporating a range of types of different dairy cattle groupings [experiment 1 (E1), 126 outdoor lactating dairy cows; experiment 2 (E2), 120 housed lactating dairy cows; experiment 3 (E3), 18 housed dairy calves; and experiment 4 (E4), 22 housed dairy bulls] from which a subset of individuals were permanently removed $(\mathrm{E} 1, \mathrm{n}=7 ; \mathrm{E} 2, \mathrm{n}=5 ; \mathrm{E} 3$, $\mathrm{n}=9 ; \mathrm{E} 4, \mathrm{n}=18)$. Associations between individuals were established using near-neighbor scores (based upon identities and distances between animals recorded before removal) in E1, E2, and E3. Behavioral recordings were taken for 3 to $5 \mathrm{~d}$, before and after removal on a sample of cattle in all 4 experiments $(\mathrm{E} 1, \mathrm{n}=20$; $\mathrm{E} 2, \mathrm{n}=20 ; \mathrm{E} 3, \mathrm{n}=9 ; \mathrm{E} 4, \mathrm{n}=4)$. In 2 experiments with relatively large groups of dairy cows, E1 and E2, the responses of cows that did and did not associate with the removed cows were compared. An increase in time that both nonassociates and associates spent eating was observed after conspecific removal in E1. In E2, this increase was restricted to cows that had not associated with the removed cows. A reduction in ruminating in remaining cattle was observed in E3 and eating in E4. Immunoglobulin A concentrations increased after separation in both E3 and E4 cattle, but did not differ significantly between associates and nonassociates in E2. Blood and milk cortisol concentrations were not affected by conspecific removal. These findings suggest

Received October 5, 2014

Accepted August 5, 2015.

${ }^{1}$ Corresponding author: jwalker@unitec.ac.nz that some animals had affected feeding behavior and $\operatorname{IgA}$ concentrations after removal of conspecifics.

Key words: association, dairy cattle, separation, immunoglobulin A, conspecific

\section{INTRODUCTION}

Increasingly, animal emotions form the basis of animal welfare definitions (Dawkins, 1990; Fraser and Duncan, 1998; Mendl and Paul, 2004; Broom, 2010), with public concern for the welfare of farm animals often arising from the recognition that animals are able to experience emotions (Špinka, 2012; Boissy and Erhard, 2014). Farm animals are gregarious and their social environment plays a fundamental role in the individual's welfare status (Keeling and Gonyou, 2001; Rault, 2012), with many benefits being derived from the presence of a conspecific (Rault, 2012). Dairy cattle form long lasting social bonds (Reinhardt and Reinhardt, 1981; Færevik et al., 2006) and show strong affiliation to conspecifics (Holm et al., 2002). In modern production systems, the regrouping of cattle [regrouping is defined here as a 2-step process: (1) Separation from the old group and (2) introduction to a new group] occurs frequently to create homogenous groups organized by common characteristics, such as age, milk yield, body condition, reproduction, and health status (Bøe and Færevik, 2003; Raussi et al., 2005). This regrouping process, in particular step 2 , has been documented to result in social stress evidenced by behavioral changes that include increased aggression (Raussi et al., 2005), vocalizations (Boissy and Le Neindre, 1997; Færevik et al., 2006; De Paula Vieira et al., 2010), and changes in locomotory behavior (Hasegawa et al., 1997; von Keyserlingk et al., 2008) and has negative effects on production traits, such as reduced feed intake (von Keyserlingk et al., 2008; De Paula Vieira et al., 2010; Schirmann et al., 2011; Duve et al., 2012), milk yield (Hasegawa et al., 1997; von Keyserlingk et al., 2008), 
and weight gain (De Paula Vieira et al., 2010). These negative effects have been documented across a range of cattle scenarios including lactating cows, heifers, and bulls (Mench et al., 1990; Hasegawa et al., 1997; Mounier et al., 2006). However, studies investigating the effect of repeated regrouping show contradictory findings, with some suggesting cattle do habituate to regrouping over time (Mench et al., 1990) and others providing no evidence of this (Raussi et al., 2005). Conceivably the stability of relationships between the cattle and the number of animals affected by the regrouping may determine the ability of cattle to habituate to the practice.

The majority of studies investigating the regrouping of cattle have focused on the effect on the individual(s) being regrouped (e.g., Mench et al., 1990; Raussi et al., 2005; Mounier et al., 2006; von Keyserlingk et al., 2008). In these studies the effects of separation are often hard to distinguish from the effects of the novel environment (Rault, 2012). Although the effect of new individuals introduced to a previously established group has been described, the effect on the individual(s) remaining in the original group has not. In one study by Schirmann et al. (2011), the difference in response to regrouping between cows that were moved to a new pen and those that stayed in their home pen was investigated; however, due to the experimental design, the effects of removal of individual cows on those remaining in the home pen could not be separated from the effects of the newly introduced cows.

Measurement of stress traditionally involves behavioral observation and physiological evaluation of, for example, hypothalamic-pituitary-adrenal (HPA) activation (e.g., cortisol) or immunological response (e.g., IgA). Immunoglobulin A represents a main element of the humoral immune response, which provides protection against pathogens at mucosal surfaces (Snoeck et al., 2006). In its secretory form (S-IgA), it serves to prevent infective agents such as bacteria and viruses from breaching the mucosal barrier, whereas within serum it functions as an inflammatory antibody acting on immune effector cells (Snoeck et al., 2006). Relatively little information is available on the relationship between IgA and stress responses in farm animals, with the exception that in pigs S-IgA reportedly increases as a result of chronic stress caused by social isolation during the first $12 \mathrm{~d}$ and declines thereafter (Royo et al., 2005). A similar response has been observed in dogs in the first $6 \mathrm{~d}$ following separation from a conspecific (Walker et al., 2014) and as a result of stress experienced upon entry into a kennel environment (Skandakumar et al., 1995). In response to acute stress, S-IgA levels in rats and dogs have been documented to decrease (Guhad and Hau, 1996; Kikkawa et al., 2003), and in humans a large body of evidence concludes that negative emotional valence, resulting from shortterm stress, results in decreased S-IgA (reviewed by Segerstrom and Miller, 2004). Although the influence of emotional states on IgA secretion in cattle has not been examined, bovine IgA has been quantified in milk (Newby and Bourne, 1977; Honkanen-Buzalski and Sandholm, 1981), and serum, lacteal, saliva, nasal, and vaginal secretions (Duncan et al., 1972). Research has demonstrated that IgA in bovine milk is predominantly serum derived (Newby and Bourne, 1977), suggesting that milk could act as an appropriate, noninvasive, accessible alternative to serum in the measurement of short- and long-term stress. Likewise, cortisol concentrations in milk from cows in established lactation have been demonstrated to directly relate to cortisol concentrations in blood (Shutt and Fell, 1985), suggesting that milk is a suitable substitute for serum when measuring cortisol concentrations in dairy cattle.

The objective of this study was to investigate the effect of step 1 of regrouping: The effect that the removal of individuals from the group has on remaining group members, using behavior observations and 2 physiological measures: cortisol and IgA.

\section{MATERIALS AND METHODS}

These experiments were approved by the University of Queensland Animal Ethic Committee (approval numbers CAWE139/10 and CAWE068/11).

\section{Experiment 1}

Animals. In experiment 1 (E1), observations were made of a herd of 126 lactating Holstein-Friesian and mixed breed dairy cows at the University of Queensland (Gatton, Queensland, Australia). The study was carried out during mid-winter (mean temperature $=16^{\circ} \mathrm{C}$ $\pm 4.4^{\circ} \mathrm{C}$ ) when the herd was maintained in a 1.93-ha outdoor feedlot area (Figure 1), with a stocking density of 65.3 cow per ha. Of the total 126 cows, $55 \%(69 / 126)$ were Holstein-Friesian; 27\% (34/126) Holstein-Friesian crossbreed; one (0.8\%) each of Jersey, Brown Swiss, Brown Swiss cross Jersey, Ayrshire cross, and the remaining 15\% (19/126) were of unknown crossbreed.

The group structure was dynamic with cows temporarily removed from the herd as a result of cessation of lactation, illness, or estrus cycle, as well as for use during agriculture and veterinary teaching demonstrations and practicals. The cows were milked twice daily in a herringbone parlor between 0600 to $0800 \mathrm{~h}$ and 1500 to 1800 h. Feed was delivered twice daily at 0800 and 1300 
$\mathrm{h}$ to a covered feeding trough in a paddock. The cows were maintained on a TMR consisting of $13 \%$ soybean meal, $38 \%$ grain mix, $26 \%$ barley silage, $14 \%$ soybean silage, $6 \%$ lucerne silage, and $3 \%$ mineral mix on a DM basis. The feed bunk was $60 \mathrm{~m}$ long with enough room for all cows to feed comfortably at the same time. Water was available ad libitum.

Near-Neighbor Observations. A subset of 7 individuals were selected for removal and subsequent culling due to age-related reductions in milk production. Nearest neighbor identities and distances were recorded before this removal to establish the strength of associa- tion between these removed individuals and others in the group. The distance from each of the 7 individual cows signaled for removal, to up to 5 nearest neighbors, was estimated visually using cow length (mid-point between the shoulder and tail of the cow shoulder to rump; Gibbons et al., 2010) as a guide. Near-neighbor observations were carried out on 34 to $39(\mathrm{SD}=1.7)$ occasions, for each of the 7 focal animals, over $9 \mathrm{~d}$ in 3 differing locations: the paddock, order of entry into the milking parlor, and during feeding. Recordings in the paddock were conducted between 0900 to $1300 \mathrm{~h}$ (with at least $1 \mathrm{~h}$ between recording sessions) on 21

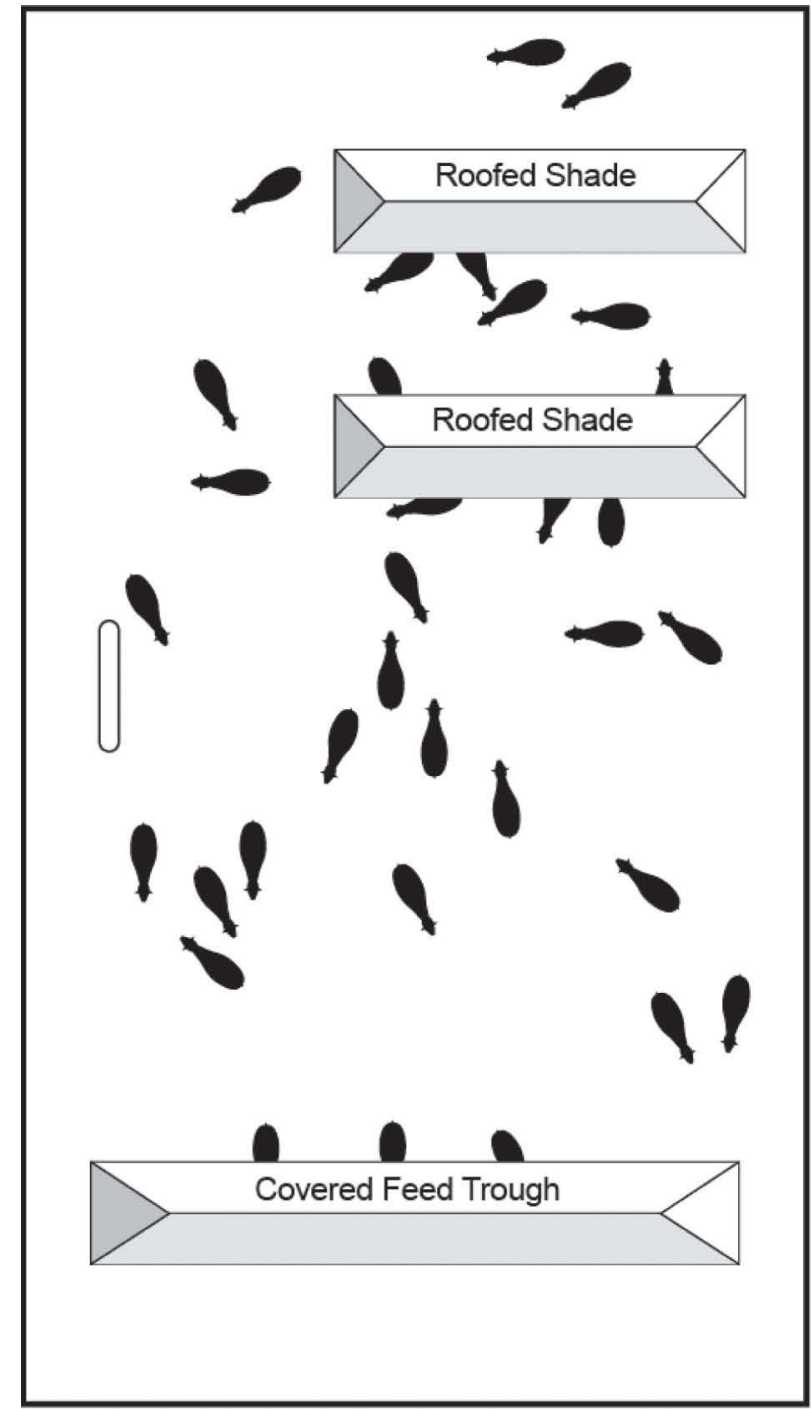

Experiment 1

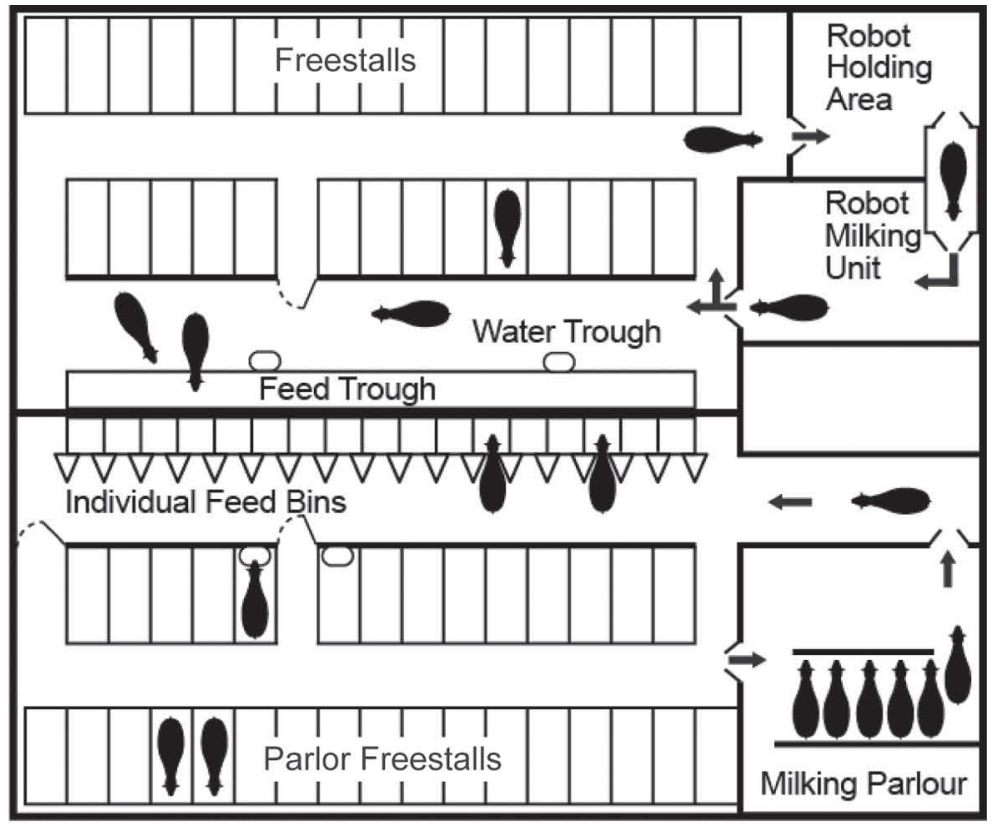

Experiment 2

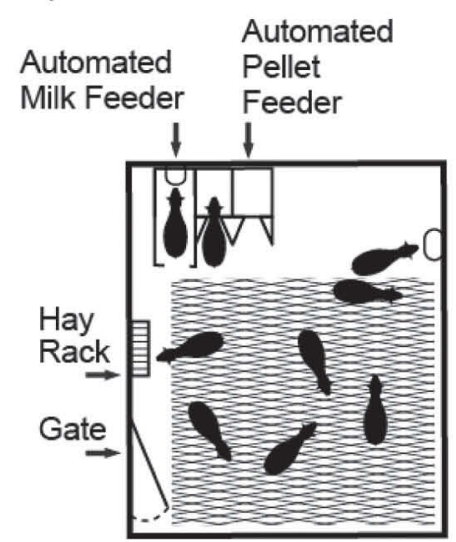

Experiment 3
Experiment 4

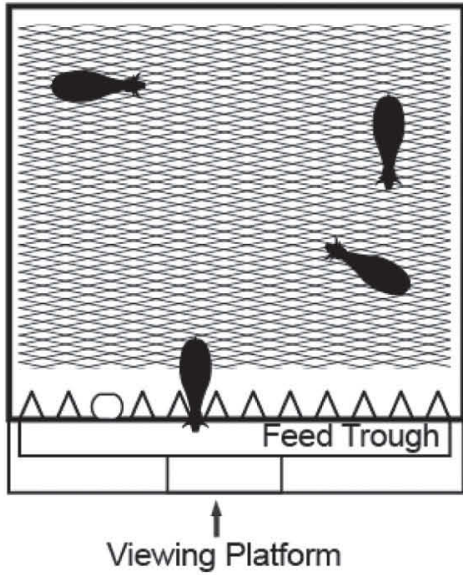

\section{KEY MUM Area of straw bedding $\bigcirc \quad$ Water Trough}

Figure 1. Overhead view of experimental facilities. Number of cattle does not represent exact experimental numbers in experiment 1 and 2. 
to 24 ( $\mathrm{SD}=1.1$ ) occasions/cow over $9 \mathrm{~d}$. Order of entry into the milking parlor recordings were carried out on 3 to $5(\mathrm{SD}=0.9$ ) separate occasions per cow at the p.m. milking, with the cow on either side of each focal cow recorded. Cows at the end of a milking row had only one recorded neighbor. Feeding recordings followed the methodology described by Cooper et al. (2008), with cows each observed on 8 to $10(\mathrm{SD}=0.8)$ occasions across 9 d between 1300 to $1500 \mathrm{~h}$, following the delivery of the afternoon feed ration. The 2 nearestneighbors on either side of each focal cow were recorded and considered feeding partners, providing they were within a distance of 1 cow length. If a cow was at the end of the feeding line, she was considered to only have one feeding partner. Observations were carried out in these 3 locations because these were the only locations that the cows had access at set times across a 24-h day.

Selection of Experimental Subjects. To allocate subjects to an associate or a nonassociate group, we used the near-neighbor recordings to identify the 10 individuals that displayed the greatest (associate), and the 10 individuals that displayed the weakest (nonassociate), association to the 7 individuals identified for removal. Probability theorem was used to establish that these interactions did not occur by chance (see Statistical Analysis section). The number $(n=10)$ of individuals allocated to both the associate and nonassociate groups was determined from the natural social structure of cattle which is reported to be a mean group size of 10 to 11 individuals (Bouissou et al., 2001). The 20 selected cows had mean age of $6.1 \pm 1.8$ (SD) yr and weight of $577 \pm 144.5$ (SD) kg. The mean milk yield per experimental cow was $27.1 \pm 7.9$ (SD) L per day during the course of the experiment. Stocking density after removal was 60 cows per ha.

Behavioral Observations. An ethogram (Table 1) was developed based on previous studies (Krohn, 1994; Fröberg and Lidfors, 2009; Fogsgaard et al., 2012). Behavioral observations were carried out by 3 trained observers, 2 of whom were recording at any one time. Observations were made continuously using focal animal sampling for each of the 20 cows, at 1-h intervals, for a $10 \mathrm{~min}$ per cow duration. Cows were recorded in the same order each time. Observations were carried out continuously for $8 \mathrm{~d}$ between morning and afternoon milking from 0800 to $1500 \mathrm{~h}$ (70 min per day/per cow), $4 \mathrm{~d}$ being before removal of designated cows (d $-5,-3,-2,-1)$, and the remaining $4 \mathrm{~d}$ after removal

Table 1. Behavioral categories and subcategories and their definitions

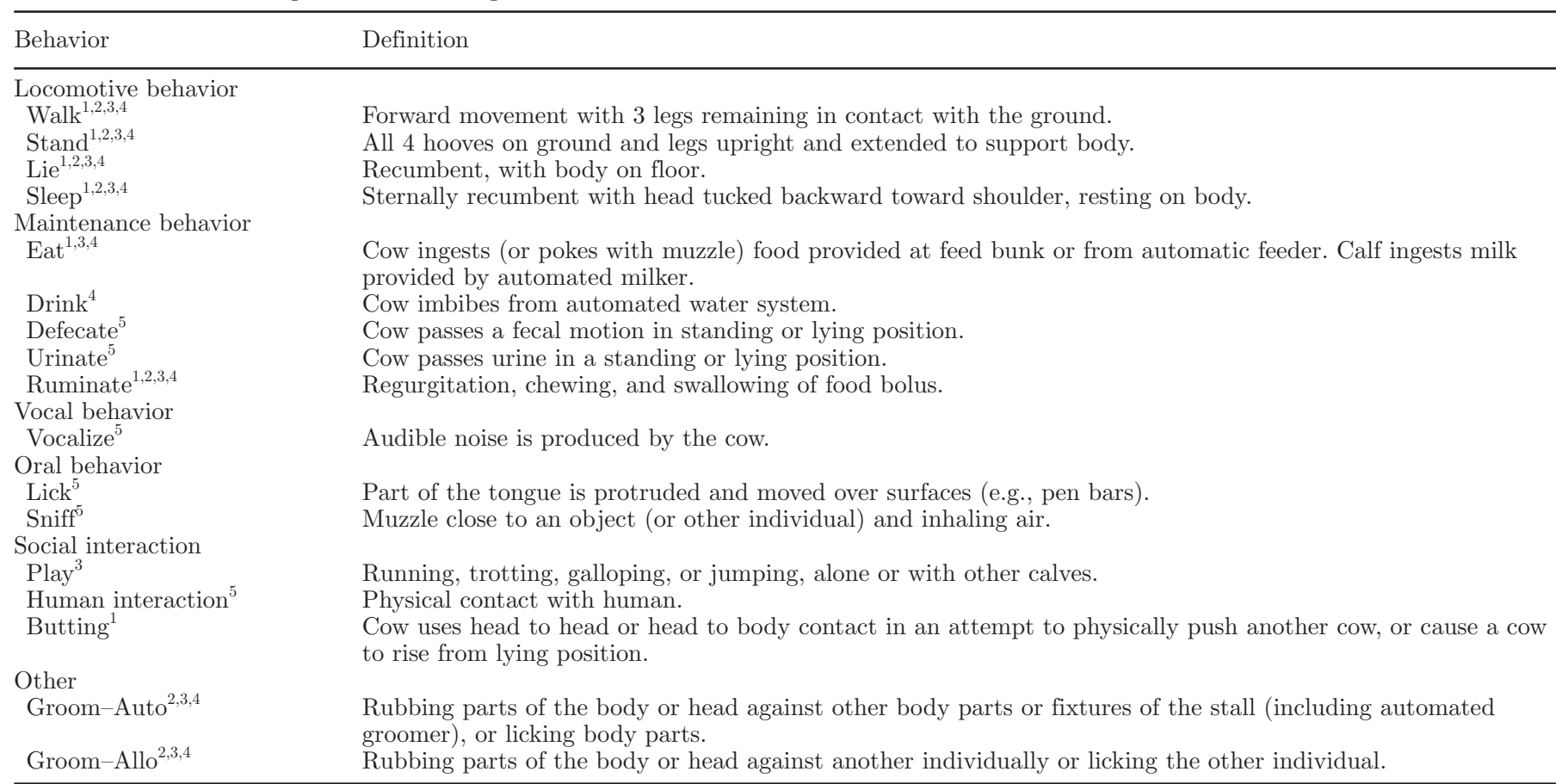

${ }^{1}$ Behaviors analyzed in experiment 1.

${ }^{2}$ Behaviors analyzed in experiment 2 .

${ }^{3}$ Behaviors analyzed in experiment 3 .

${ }^{4}$ Behaviors analyzed in experiment 4 .

${ }^{5}$ Behaviors not included in analysis due to infrequency of occurrence. 
$(\mathrm{d}+1,+2,+3,+4)$. Removal took place at $1900 \mathrm{~h}$; therefore, the first observations after separation began $13 \mathrm{~h}$ postseparation.

\section{Experiment 2}

Animals. Experiment 2 (E2) was carried out at the Estonian University of Life Sciences Maarja Farm, Tartu, Estonia. Observations were made of 2 herds each containing 60 lactating Holstein-Friesians, each with a stocking density of 0.12 cows per $\mathrm{m}^{2}$. Cows in both herds were free-stall housed within the same building and fed cut grass in their housing (Figure 1). The total housing area for both herds was $1,032 \mathrm{~m}^{2}$. The group structure was dynamic with cows temporarily removed for cessation of lactation, illness, or estrus. Milking occurred twice daily in either a traditional parlor $(\mathrm{n}=8)$ at 0530 and $1500 \mathrm{~h}$ or twice daily in a robotic milking system $(\mathrm{n}=12)$. The 2 differing milking systems were engaged for teaching demonstrations and research purposes. Cows had ad libitum access to water and were fed a TMR consisting of grass/clover silage $50.8 \%$ DM, barley $24.6 \% \mathrm{DM}$, wheat $7.8 \% \mathrm{DM}$, rapeseed cake $15 \%$ $\mathrm{DM}$, and mineral feed $1.8 \% \mathrm{DM}$. They were fed twice daily at 1000 and $1700 \mathrm{~h}$. The parlor-milked cows had individual access to bins in their housing (Figure 1) with varying amounts of added concentrate in TMR. Robot-milked cows received an additional 0.88 to 2.64 $\mathrm{kg}$ of $\mathrm{DM} / \mathrm{d}$ of concentrate supplement (Baltic Argo AS, Tallinn, Estonia) from an automated feeder and 2.64 to $5.28 \mathrm{~kg} \mathrm{DM} / \mathrm{d}$ in the robot, according to yield.

Near-Neighbor Observations. A subset of 5 individuals (parlor-milked herd $\mathrm{n}=2$; robot-milked herd $\mathrm{n}=3$ ), with a mean age of $3.8 \pm 0.84(\mathrm{SD}) \mathrm{yr}$, was identified for removal due to imminent dry-off and forthcoming parturition. Stocking density after removal in $\mathrm{E} 2$ was 0.11 cow per $\mathrm{m}^{2}$ for both the parlor-milked and robot-milked herds. An additional subset of 5 individuals (parlor-milked herd, $\mathrm{n}=2$; robot-milked herd, $\mathrm{n}=3$ ), with a mean age of $4.6 \pm 1.1$ (SD) yr, was randomly selected to aid in establishment of a control group. Nearest-neighbor distances were determined for all 10 cows before removal of the subset of 5 individuals mentioned above. The near-neighbor observations were carried out in loose housing area that included the feed bunk (Figure 1) using the methodology described in E1, with the exception that to be considered a near neighbor the cow had to be within 1 cow length of the focal animal (rather than 3) due to the more intensive housing conditions. Observations were not carried out separately during milking or at the feed bunk, as was done in E1, due to the use of the robot milking system and the inclusion of the feed bunk in the loose housing area. Near-neighbor observations were carried out on
12 occasions at $1300,1900,2400$, and $0500 \mathrm{~h}$ across 3 consecutive days. These occasions represented even distribution across each 24 -h period while also incorporating a 2-h period after milking (parlor side) and feeding before the start of an observation session.

Selection of Experimental Subjects. A subgroup of 20 individuals (parlor, $\mathrm{n}=8$; robot milkers, $\mathrm{n}=$ 12) was selected as outlined below and divided into 2 groups of 10. Selection used near-neighbor recordings to first identify the 10 individuals that displayed the strongest association to the 5 individuals signaled for subsequent removal. These 10 individuals formed the associate group [mean age $3.3 \pm 1.4(\mathrm{SD}) \mathrm{yr}$. To create a nonassociate group, 5 individuals from the herd (other than those signaled for removal) were selected at random and the 10 individuals with the strongest nearneighbor association to these formed the nonassociate group [mean age $4.0 \pm 1.10$ (SD) yr]. This method of selection differed from E1 to control for the possibility that our methodology in E1 may have inadvertently selected cows that were less sociable to all cows, not just the removed cows. Hence in E2 we chose cows that were equally sociable, but to different cows, for our nonassociate group.

Behavioral Observations. The same ethogram detailed in E1 was used in E2. Behavioral observations of the selected subgroup of 20 individuals were carried out by the lead researcher from a viewing platform above the housing area for $3 \mathrm{~d}(\mathrm{~d}-6,-4,-2)$ before removal of preselected individuals and $3 \mathrm{~d}(\mathrm{~d}+1,+3,+6)$ after removal. Observations were conducted using instantaneous scan sampling (Martin and Bateson, 1993) at 10-min intervals for a 2-h duration at 0200, 1000, and $1800 \mathrm{~h}$, totaling 36 scans per day.

Physiological Sample Collection. Milk samples were collected from each of the 20 cows, using polypropylene centrifuge tubes (Brand $\mathrm{GmbH}+\mathrm{Co} \mathrm{KG}$, Wertheim, Germany), during p.m. milking between 1500 to $1600 \mathrm{~h}$ on $\mathrm{d}+1,+3,+6$. Samples were centrifuged immediately for $10 \mathrm{~min}$ at $5,000 \times g$ at room temperature and skim milk was extracted and frozen at $-25^{\circ} \mathrm{C}$ for subsequent determination of IgA and cortisol concentrations.

\section{Experiment 3}

Animals. Experiment 3 (E3) was carried out at the same farm as E2 with observations of 9 HolsteinFriesian dairy calves, maintained on the farm within a group of 18 calves [mean age $65 \mathrm{~d} \pm 16.8 \mathrm{~d}$ (SD)]. The group of 18 calves were housed together continuously in a straw and peat-bedded pen $(4.5 \mathrm{~m} \times 3.5$ $\mathrm{m}$; stocking density $=1.1$ calf per $\mathrm{m}^{2}$; Figure 1 ) from approximately 2 wk after birth and maintained on milk 
replacer (Denka Milk, Voorthuizen, the Netherlands) fed at levels up to $8 \mathrm{~L} / \mathrm{d}$ at 8 wk of age, obtained from an automatic milk feeder. Levels of milk intake were not recorded. Hay was provided ad libitum, and pellets (Saldus Labiba, Saldus, Latvia) were provided at up to $1.72 \mathrm{~kg}$ of $\mathrm{DM} / \mathrm{d}$, according to live weight, and accessed from an automatic feeder. All individuals had ad libitum access to water. A subset of nine 8-wk-old calves were identified for removal into older age groupings. The remaining 9 calves had a mean age of $36 \pm 9.8 \mathrm{~d}$ (SD). The stocking density after removal was 0.6 calves per $\mathrm{m}^{2}$. Near-neighbor observations were not possible due to the small numbers of calves in this study.

Behavioral Observations. The same ethogram detailed in E1 was used in E3 with the addition of play behavior. Behavioral observations of the 9 calves were carried out by a single observer from a viewing area fronting the housing area for $3 \mathrm{~d}(\mathrm{~d}-5,-3,-1)$ before and $3 \mathrm{~d}(\mathrm{~d}+1,+3,+6)$ after removal of preselected individuals. Observations were conducted using instantaneous scan sampling (Martin and Bateson, 1993) at 10-min intervals for $2 \mathrm{~h}$ at 1100 and $1700 \mathrm{~h}$, totaling 24 scans per day

Physiological Sample Collection. As milk samples were unable to be collected from this group, blood samples were collected by a veterinarian from the coccygeal vein on each of the 9 calves, using heparinized tubes (Venoject, Terumo Corporation, Leuven, Belgium), between 1000 and $1100 \mathrm{~h}$ on $\mathrm{d}-1,+1,+3$, and +6 . Samples were centrifuged immediately for 20 min at 5,000 $\times g$ at room temperature, and serum was extracted and frozen at $-25^{\circ} \mathrm{C}$ for subsequent determination of $\operatorname{Ig} \mathrm{A}$ and cortisol concentrations.

\section{Experiment 4}

Animals. Experiment 4 (E4) was conducted on a commercial dairy farm in Rahinge, Estonia. Subjects consisted of four 16-mo-old Holstein-Friesian bulls, maintained in a group of 22 (stocking density $=0.3$ bulls per $\mathrm{m}^{2}$ ). They had been housed together continuously since around $8 \mathrm{wk}$ of age and were loose housed in a deep straw pen $\left(70 \mathrm{~m}^{2}\right)$ within a larger barn (Figure 1 ). The animals had ad libitum access to water and were maintained on a TMR consisting of grass/clover silage, hay $(83 \% \mathrm{DM})$, and commercial pellets $(300 \mathrm{~g} / \mathrm{d}$, $86 \% \mathrm{DM}$ ), fed at 0900 and $1700 \mathrm{~h}$. A subset of 18 of the bulls were selected for removal based on qualification for live export. Stocking density after removal was 0.06 bulls per $\mathrm{m}^{2}$.

Behavioral Observations. Observations were carried out from a viewing platform above the group using the same ethogram as in E1. The 4 bulls were observed using focal animal sampling (Martin and Bateson,
1993) for 15-min durations, at 1-h intervals, between 1000 and $1800 \mathrm{~h}$ (totaling $2 \mathrm{~h}$ of per bull/per day) on $4 \mathrm{~d}(\mathrm{~d}-7,-4,-2,-1)$ before and after $(\mathrm{d}+1,+3$, $+5,+7)$ removal. Near-neighbor observations were not possible due to the small numbers of bulls in this study.

Physiological Sample Collection. As milk samples were unable to be collected from this group, blood samples were collected by a veterinarian from the coccygeal vein, using heparinized tubes (Venoject, Terumo Corporation) on each of the 4 bulls animals between 1000 and $1100 \mathrm{~h}$ on $\mathrm{d}-1,+1,+3$, and +5 . The bulls were restrained in a holding corner of their home pen during sample collection. Samples were centrifuged immediately for $20 \mathrm{~min}$ at $5,000 \times \mathrm{g}$ at room temperature, and serum was extracted and frozen at $-25^{\circ} \mathrm{C}$ for subsequent determination of $\operatorname{IgA}$ and cortisol concentrations.

Identification. Individuals in all experiments were numerically identified (on both the head and rump) using tail paint [FIL Tell Tail, Farmers Industries Limited, Mount Maunganui, New Zealand (E1) or Porcimark Maerkespray, Kruuse (E2, E3, and E4)].

Physiological Sample Analysis. To calculate IgA concentration, the optical density of samples was compared with the optical density of a standard with a known concentration of $\operatorname{Ig} \mathrm{A}$, using the Bovine $\operatorname{Ig} \mathrm{A}$ ELISA Quantitation Kit (E103, Bethyl Laboratories, Montgomery, TX). The ELISA plates were coated with $100 \mu \mathrm{L}$ /well of diluted anti-bovine IgA antibody (E10-121, Bethyl Laboratories) and incubated at room temperature for $60 \mathrm{~min}$ diluted to $1 \mu \mathrm{g} / \mathrm{mL}$ in carbonate-bicarbonate buffer at $\mathrm{pH}$ 9.5. Plates were washed 5 times with wash solution $(50 \mathrm{~m} M$ Tris, 0.14 $M \mathrm{NaCl}, 0.5 \mathrm{~mL} / \mathrm{L}$ of Tween20, distilled water). Plates were then blocked for $30 \mathrm{~min}$ at room temperature with $200 \mu \mathrm{L}$ /well of blocking solution (50 $\mathrm{m} M$ Tris, $0.14 M$ $\mathrm{NaCl}$, distilled water, $1 \% \mathrm{BSA}$ ) added to each well and incubated at room temperature for $30 \mathrm{~min}$. Plates were washed 5 times and $100 \mu \mathrm{L} /$ well of diluted standards or samples was added. Then, $1.5 \mu \mathrm{L}$ of sample was diluted in $1.5 \mathrm{~mL}$ of diluent, based on the expected concentration (sample dilute: $50 \mathrm{~m} M$ Tris, $0.14 \mathrm{M} \mathrm{NaCl}$, $0.5 \mathrm{~mL} / \mathrm{L}$ Tween20). Samples were diluted starting at 1:1,000 and extending to 1:156,000. Plates were incubated at room temperature for an additional $60 \mathrm{~min}$ and then washed 5 times, followed by the addition of $100 \mu \mathrm{L} /$ well of diluted anti-bovine IgA horseradish peroxidase antibody E10-121, (Bethyl Laboratories) and incubation at room temperature for an additional 60 min. Plates were washed an additional 5 times and 100 $\mu \mathrm{L} /$ well of tetramethylbenzidine substrate solution was added, with a stop solution $\left(0.18 M \mathrm{H}_{2} \mathrm{SO}_{4}\right.$ at $100 \mu \mathrm{L} /$ well) added after $5 \mathrm{~min}$. Optical density was read at 450 $\mathrm{nm}$ with a microplate reader (IL650, Instrumentation 
Laboratory, Cheshire, UK). The concentration of IgA in each sample was calculated using linear regression from a standard curve generated from the standards using IL650 software. The IgA results are reported in milligrams per deciliter of serum/milk.

Cortisol concentrations were quantified with a solid phase competitive chemiluminescent enzyme immunoassay (Immulite 1000, Siemens Medical Solutions Diagnostics, Camberley, UK) using a commercial kit (Immulite Cortisol Kit, Siemens Medical Solutions Diagnostics). Results for the cortisol were generated from the standard curves produced within the Immulite 1000. The cortisol detection limit was $27.6 \mathrm{mmol} / \mathrm{L}$.

All samples were analyzed by CTDS Veterinary Diagnostic Laboratory, Leeds, UK. The within assay coefficients of variability for serum and skim milk were 6.1 and $1.4 \%$ (cortisol) and 10.1 and $3.9 \%(\operatorname{IgA})$, respectively. The between-assay coefficients of variation for serum and skim milk were 8.15 and $4.4 \%$ (cortisol) and 16.6 and $5.2 \%(\operatorname{IgA})$, respectively.

\section{Statistical Analysis}

All values are reported as means \pm standard deviations. To establish the nearest neighbors in E1, a clustering of the observations using a dendrogram was performed. From this we identified the 10 individual cows (associate group) that had the closest associations with the 7 focal cows signaled for removal. For the nonassociate group, the 10 cows with the weakest associations with the focal cows were selected from the cluster analysis. To confirm that these interactions did not simply occur by chance, the probability of an individual member of the herd being recorded with one of the 7 focal cows on either 2 or 3 occasions out of the total number of observations was calculated using the probability theorem (Cooper et al., 2008). To summarize, the chance of each focal cow interacting with any other cow on any observation was 125/125 (125 cows were used because this was the number of cows any focal cow could interact with). The chance of the focal cow interacting on the subsequent observation with the same cow was $1 / 125$, and with a different cow in the herd was $124 / 125$. On the second observation, the chance of the focal cow interacting with a different cow, except the first or second, was $123 / 125$, and so on. This process continued until the remaining number of terms was equal to the total number of observations that took place (e.g., 36 for focal cow 1). This is numerically expressed as

$$
\begin{gathered}
125 / 125 \times 1 / 125 \times 124 / 125 \times 123 / 125 \\
\times 122 / 125 \ldots 91 / 125=125 ! / 90 !
\end{gathered}
$$

where $!=$ factorial. The number of places cow 1 could appear was $36 ! / 2 ! / 34$ !

The probability of 2 cows occurring together on 2 occasions, out of a possible 36 , is

$$
125 ! / 90 ! \times 1 / 125^{36} \times 36 ! / 2 ! / 34 !=0.026 .
$$

The probability of 2 cows being observed together on 3 occasions was similarly calculated as $125 ! / 91 ! \times 1 / 125^{36}$ $\times 36 ! / 3 ! / 33 !=0.003$.

In E2 and E3, near-neighbor associations were calculated using the association equation of Martin and Bateson (1993):

$$
\begin{gathered}
\text { near-neighbor score }=\text { (number of times cow } \\
\text { has been near-neighbor of focal cow)/ }
\end{gathered}
$$$$
\text { (number of focal cow observations). }
$$

Data were analyzed using Minitab (version 16, Minitab Inc., State College, PA). For all experiments, descriptive analysis of the recorded behavioral subcategories was carried out and any behavior occurring infrequently (n $<3$ ) was removed. All behavior subcategories retained for analysis within each experiment (Table 1) were converted to a proportion per day due to variations in the total number of observations. The data mostly followed a normal pattern of distribution (Anderson Darling $P$ $>0.05)$ and where deviations from normality occurred the data were transformed using square root or $\log _{10}$ as appropriate. The different measures of behavior across the experiments precluded the data from being pooled and analyzed together. In E2 and E3, stand and walk behaviors were combined. A general linear model was used to investigate significant changes in behavior before versus after removal within each experiment. In $\mathrm{E} 1$ and $\mathrm{E} 2$, the model included the variables before or after removal $(\mathbf{B} / \mathbf{A})$, day nested within $\mathrm{B} / \mathrm{A}$, and group (associate or nonassociate) nested within $\mathrm{B} / \mathrm{A}$. In E3 and E4, the model included B/A, each individual calf or bull and day nested within B/A. Post hoc Tukey was engaged to investigate where significance lay across days in all models. A change in the concentrations of IgA and cortisol across days was investigated using linear regression.

\section{RESULTS}

\section{Behavioral Responses}

In E1, one cow was removed from analysis due to sickness in the final days of observation. Based on the number of times the focal (removed cow) was seen with one of the associate cows, the probability of association 
Table 2. The mean percentage (and SED) of time for each behavior occurring across all days before and all days after removal for nonassociate cows $(\mathrm{n}=10)$ and associate cows $(\mathrm{n}=10)$ in experiment 1 [investigation of the effects on remaining cows as a result of removal of a small group of individuals $(\mathrm{n}=7)$ from the larger herd $(\mathrm{n}=126)]$ and the probabilities of differences before and after removal ${ }^{1}$

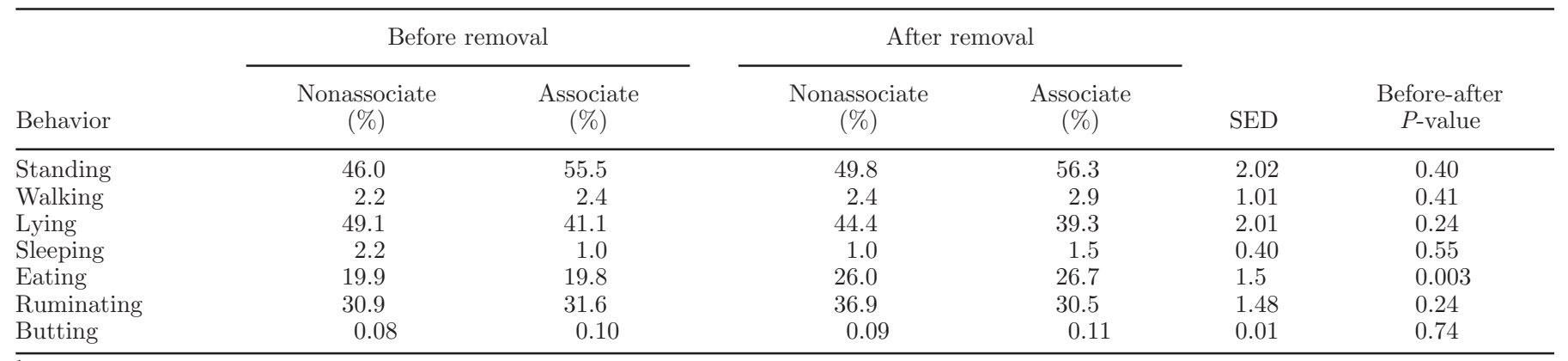

${ }^{1}$ No significant $(P \leq 0.05)$ associate vs. nonassociate effects or individual day effects were observed.

for each of the focal (removed) cows was follows: focal $\operatorname{cow}(\mathbf{F C}) 1=0.03, \mathrm{FC} 2=0.01, \mathrm{FC} 3=0.01, \mathrm{FC} 4=$ $0.04, \mathrm{FC} 5=0.01, \mathrm{FC} 6=0.01$, and FC7 $=0.0002$. None of the nonassociate cows were recorded with the focal cows on more than one occasion. The chance that any 2 cows would be observed together on 2 or 3 occasions were small, 0.025 and 0.0035 , respectively; therefore, the nearest-neighbor associations were considered real and not by chance. An increase $(F=9.47$, df $=1, P=$ 0.003 ) was observed in time spent eating (Table 2) after the separation, with no difference between the response of associate and nonassociate cows $(P=0.96)$, which suggests that the removal of cows influenced the eating behavior of remaining cows independent of measured associations between individuals (Table 2). No differences $(P \geq 0.24)$ were observed in time spent standing, walking, lying, sleeping, ruminating, or butting after separation (Table 2). No effect of day $(P>0.05)$ on time spent performing any of the recorded behavior was observed.

In E2, an overall increase $(F=4.37, \mathrm{df}=1, P=$ 0.04 ) was found in time that remaining cows spent eating (Table 3) after separation; however, this was only in the nonassociate cows (Tukey $P=0.02$ ), not the associate cows (Tukey $P=0.99)$. No change $(P \geq 0.34)$ was observed in time spent in any other behavior after separation (Table 3$)$. No effect of day $(P>0.05)$ on the occurrence of any recorded behavior was found.

In E3, a reduction in ruminating behavior was observed after separation $(F=7.97$, df $=1, P=0.007$; Table 4), with no change in time spent in any other behavior after separation. No effect of day $(P>0.05)$ was found on the occurrence of any behavior recorded in E3.

In E4, a decrease in eating was observed after separation in $\mathrm{E} 4(F=4.94, \mathrm{df}=1, P=0.037$; Table 5$)$. Walking was increased on $\mathrm{d}+1$ following separation, compared with d $+3,+5,+7,-7$, and $-1(F=7.63$, df $=6, P<0.0001$; all Tukey tests $P \leq 0.02$; Figure $2)$. An effect of day was observed for standing $(F=$ $2.69, \mathrm{df}=6, P=0.04)$ and sleeping $(F=2.76$, df $=$ $6, P=0.04)$; however, post hoc Tukey tests were all nonsignificant $(P \geq 0.10)$.

\section{Physiological Responses}

No difference was observed in $\operatorname{Ig} \mathrm{A}$ concentration after separation between the nonassociate and the associate group in E2 (mean nonassociate group $=113.8 \mathrm{mg} / \mathrm{dL}$; mean of associate group $=106.2 \mathrm{mg} / \mathrm{dL}, P=0.42$ ).

Table 3. The mean percentage (and SED) of recordings for each behavior occurring both before and after cow removal for nonassociate cows $(\mathrm{n}=10)$ and associate cows $(\mathrm{n}=10)$ in experiment 2 and the probabilities of differences before and after removal ${ }^{1}$

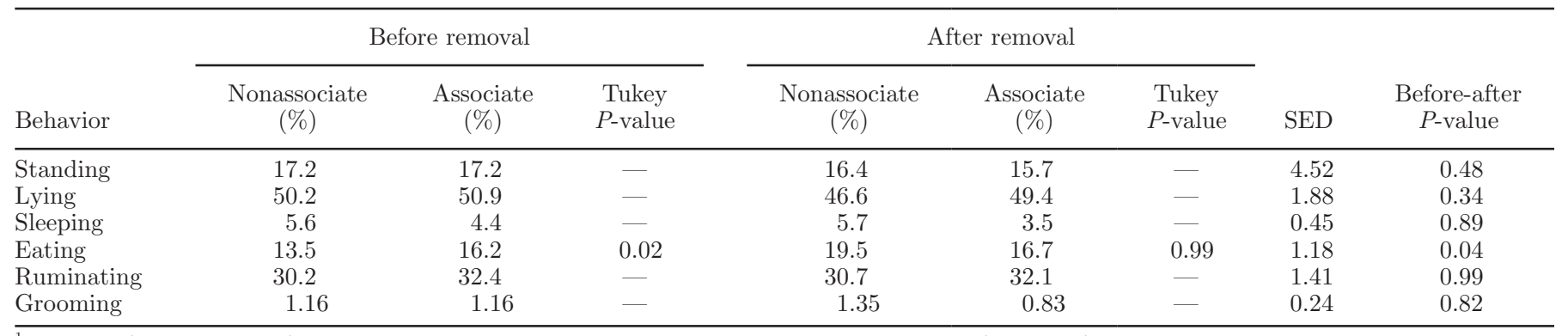

${ }^{1}$ Post hoc (Tukey $P$-value) associates vs. nonassociate effects are reported. No significant $(P \leq 0.05)$ individual day effects were observed. 
Table 4. The mean percentage (and SED) of recordings for each behavior occurring in calves $(\mathrm{n}=49)$ both before and after removal of conspecifics $(\mathrm{n}=18)$ in experiment $3^{1}$

\begin{tabular}{lcccc}
\hline Behavior & $\begin{array}{c}\text { Before removal } \\
(\%)\end{array}$ & $\begin{array}{c}\text { After removal } \\
(\%)\end{array}$ & SED & $\begin{array}{c}\text { Before-after } \\
P \text {-value }\end{array}$ \\
\hline Standing & 20.1 & 18.7 & 2.37 & 0.50 \\
Lying & 51.7 & 56.9 & 2.96 & 0.17 \\
Sleeping & 28.0 & 24.0 & 2.64 & 0.40 \\
Eating & 9.4 & 8.4 & 3.17 & 0.99 \\
Ruminating & 28.85 & 20.1 & 2.24 & 0.007 \\
Grooming & 2.12 & 3.23 & 2.45 & 0.29 \\
\hline
\end{tabular}

${ }^{1}$ No significant $(P \leq 0.05)$ individual day effects were observed.

An increase was found in $\operatorname{IgA}$ over the first $6 \mathrm{~d}$ after separation in both E3 (mean before separation $=68.2$ $\mathrm{mg} / \mathrm{dL}$; mean after separation $=83.7 \mathrm{mg} / \mathrm{dL} ; \mathrm{SED}=$ $0.78 \mathrm{mg} / \mathrm{dL} ; F=93.58, \mathrm{df}=1 ; P=0.01$ ) and $\mathrm{E} 4$ (mean before separation $=56.0 \mathrm{mg} / \mathrm{dL}$; mean after separation $=88.3 \mathrm{mg} / \mathrm{dL} ; \mathrm{SED}=3.96 \mathrm{mg} / \mathrm{dL} ; F=27.80, \mathrm{df}=1$; $P=0.03$; Figures $3 \mathrm{a}$ and $3 \mathrm{~b})$. The regression equations, with adjusted $\mathrm{R}^{2}$ and $P$-values for the coefficients for day, were

$$
\begin{gathered}
\text { E3: } y=62.0( \pm 2.02)+7.13( \pm 0.74) \mathrm{x} \\
\mathrm{R}^{2} \text { (adjusted) }=96.9 \%, P=0.01 \\
\mathrm{E} 4: \mathrm{y}=43.0( \pm 6.30)+13.2( \pm 2.51) \mathrm{x} \\
\mathrm{R}^{2} \text { (adjusted) }=89.9 \%, P=0.03
\end{gathered}
$$

where $\mathrm{y}=\operatorname{IgA}$ concentration in serum $(\mathrm{mg} / \mathrm{dL})$ and $\mathrm{x}$ $=$ day.

Cortisol concentrations did not differ in E2 between nonassociate $($ mean $=1.8 \mathrm{mM}$ ) and associate groups $($ mean $=1.7 \mathrm{~m} M ;$ SED $=0.25 \mathrm{~m} M ; P=0.79)$, E3 (mean before separation $=33.9 \mathrm{~m} M$; mean after separation $=30.1 \mathrm{~m} M ;$ SED $=1.33 \mathrm{~m} M ; P=0.19)$ or E4 (mean before separation $=27.6 \mathrm{~m} M$; mean after separation $=32.3 \mathrm{~m} M ; \mathrm{SED}=2.87 \mathrm{~m} M ; P=0.30$ ).

\section{DISCUSSION}

Social behavior is a major determinant of farm animal welfare (Keeling and Gonyou, 2001; Rault, 2012). In cattle, social behavior is characterized by the formation and maintenance of cohesive social groups (Gibbons et al., 2010). In the present study, across 4 experiments, we removed both small groups of individuals from larger groups (less than $10 \%$ of the total group) and large groups of individuals (50-80\% of the total group) to study the effect of removal on remaining group members. Overt behavioral responses were limited and physiological responses were restricted to in- creases in $\operatorname{Ig} \mathrm{A}$ concentrations in small groups of cattle, with no evidence of cortisol responses. This indicates that, unlike when individual cattle were moved into a new group, acute stress was not experienced by the remaining cattle, even when the majority of animals were removed, and supports previous studies suggesting that cattle moving to new groups habituate to repeated regroupings (e.g., Mench et al., 1990).

The observed increase in time spent eating after removal in our first 2 experiments (E1 and E2) may be the result of some dominant cows being removed from the herd, allowing subordinates more opportunities and time to feed than previously. Heifers, for example, have been demonstrated to spend more time eating and ingest greater quantities of feed when they are kept separate from older cows (Bøe and Færevik, 2003). Age is an important determinant in social positioning (Kabuga, 1992) and different types of separation (e.g., dividing a feed trough with protective barriers) have been used to improve the feeding time of subordinate cows (Bouissou et al., 2001). In E2, removed cows were

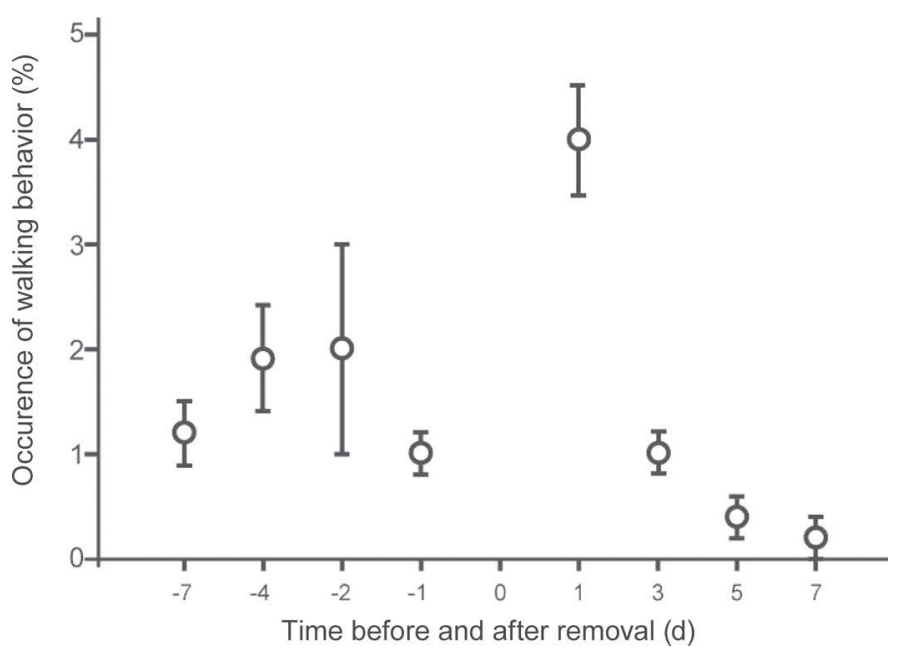

Figure 2. The percentage of walking behavior displayed across the $8 \mathrm{~d}$ of observations in experiment 4 . 
Table 5. The mean percentage (and SED) of time for each behavior occurring in bulls $(\mathrm{n}=4)$ both before and after removal in experiment 4 and the probabilities of differences before and after removal and day

\begin{tabular}{lccccc}
\hline Behavior & $\begin{array}{c}\text { Before removal } \\
(\%)\end{array}$ & $\begin{array}{c}\text { After removal } \\
(\%)\end{array}$ & SED & $\begin{array}{c}\text { Before-after } \\
P \text {-value }\end{array}$ & $\begin{array}{c}\text { Day } \\
P \text {-value }\end{array}$ \\
\hline Standing & 33.1 & 32.8 & 3.60 & 0.95 & 0.04 \\
Walking & 1.5 & 1.2 & 0.22 & 0.39 & $<0.0001$ \\
Lying & 59.0 & 55.1 & 3.84 & 0.48 & 0.29 \\
Sleeping & 4.4 & 6.6 & 1.21 & 0.21 & 0.04 \\
Eating & 15.7 & 1.8 & 2.22 & 0.04 & 0.15 \\
Drinking & 1.3 & 25.5 & 0.48 & 0.98 & 0.46 \\
Ruminating & 36.3 & 2.9 & 1.59 & 0.11 & 0.41 \\
Butting & 0.9 & 3.1 & 0.52 & 0.19 & 0.30 \\
Grooming & 1.7 & & & & 0.05 \\
\hline
\end{tabular}

on average 6 mo older than the remaining associate cows. It is also possible that this increase could have resulted from more space being available at the feed
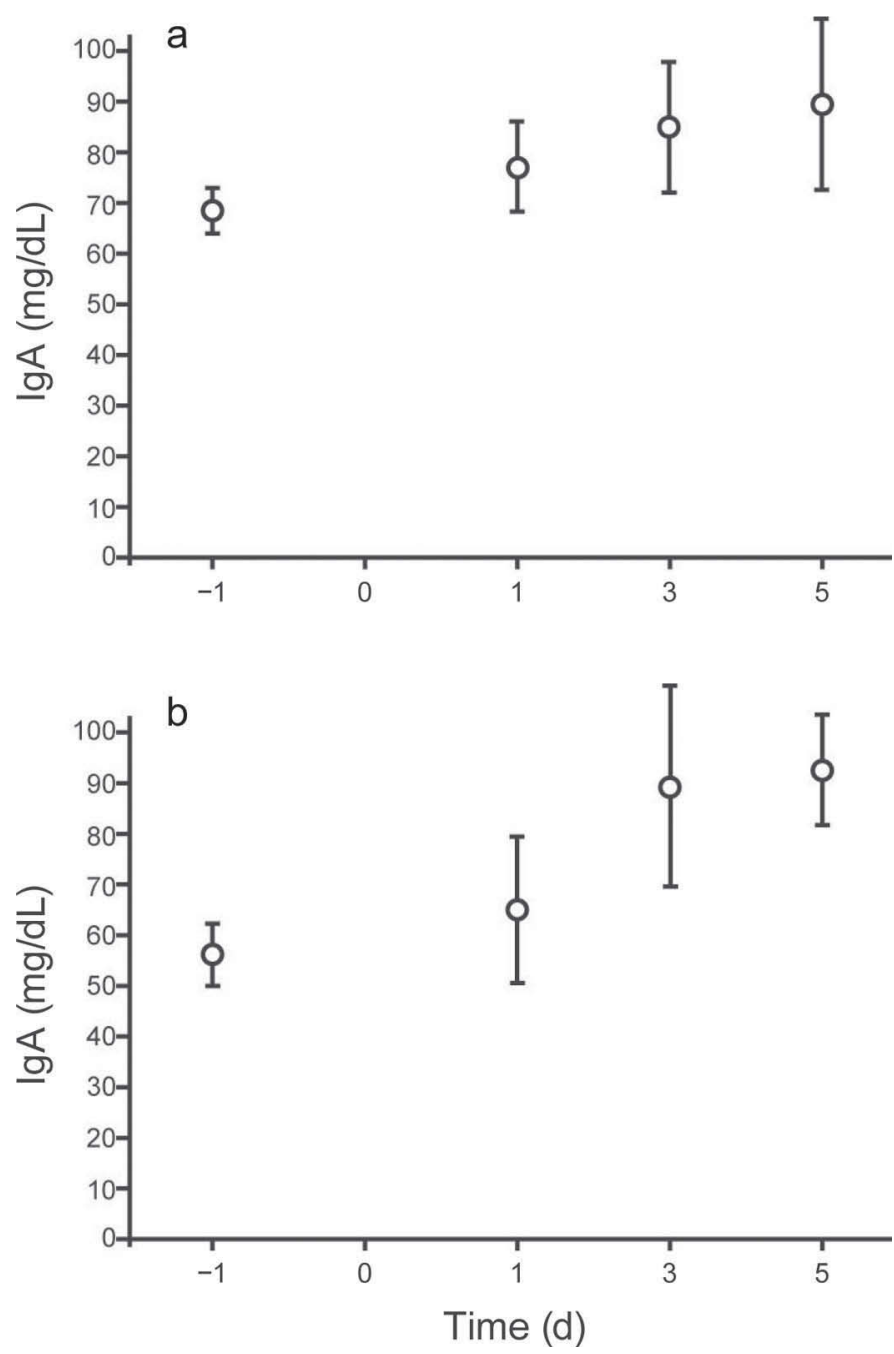

Figure 3. Mean $\operatorname{Ig} \mathrm{A}$ concentrations in experiment 3 (a; $F=93.58$, $\mathrm{df}=1 P=0.01$ ) from $\mathrm{d}-1$ (before removal) to $\mathrm{d}+1,+3$, and +6 (after removal) and in experiment $4(\mathrm{~b} ; F=27.80, \mathrm{df}=1, P=0.03$ ) across $\mathrm{d}-1$ (before removal) to $\mathrm{d}+1,+3$, and +5 (after removal). trough or that the cows were more active, resulting in increased energy expenditure and subsequently intake requirements. However, this was not supported by increased time spent walking.

In E1, the increase was observed in both the nonassociate and associate groups and suggests a herd effect. It was evident that the cows in the nonassociate group did not associate with the removed cows nor did they associate much with all other cows. Hence, the decision was made to change the nonassociate group in E2 to be cows that associated with the same frequency with cows that were not removed. In this instance, the increase in feed intake was confined to these nonassociate cows, which may suggest feeding behavior in the associate cows was suppressed, compared with the nonassociate cows, as a result of the removal of associated cows. In addition, social buffering, emotion contagion, or both could explain in part the apparent absence of observed behavioral changes. Central to sustaining good welfare for herd-living animals is the maintenance of synchronicity of behavior (Miller and Wood-Gush, 1991). From an evolutionary perspective, similarity in emotional states achieved via the sharing of emotions can be seen as advantageous, as it results in efficient coordination of behavior (Śpinka, 2012). Social buffering refers to observed reduced arousal, during stressful events, as a result of social grouping (Bouissou et al., 2001). Emotion contagion causes animals to shift their own affective state to that of other animals in a particular state (Špinka, 2012). Although understudied, animals have been evidenced to both emit and detect emotional signals, and during stressful events the social group can lower the individual's arousal (Bouissou et al., 2001). The emotional sharing and synchronicity of behavior has been most extensively studied in the social transmission of fear, which can be prevented by the presence of companions that do not show fear or vice versa (Veissier and le Neindre, 1992; Mounier et al., 2006). For example, heifers show less avoidance of unusual noise in the presence of pen mates (Boissy and 
Le Neindre, 1990), appear less fearful in novel environments when social partners are present (Veissier and le Neindre, 1992), display increased fear in either feeding or explorative situations when exposed to urine from stressed conspecifics, and show a lower tendency to feed in the presence of a stressed partner than in the presence of an unstressed one (Boissy et al., 1998). In the present study, it is possible that individuals in the associate groups E1 and E2 did not show overt behavioral signs of social stress because the majority of the group did not experience social separation or display behavioral changes.

The natural social structure of cattle is that of a group with a mean size of 10 to 11 individuals (Bouissou et al., 2001). Group living involves the formation of social relationships and preferential interactions with certain companions (Nicol, 2011), which suggests cattle are likely to form positive social relationships with more than one other individual. Social support often provides a single partner to an individual (Færevik et al., 2006; De Paula Vieira et al., 2010; Duve et al., 2012); however, as cattle naturally maintain larger groups, they require more peers to benefit from social support (Boissy et al., 1998). It is possible that the effect of the removal of a group of animals was diminished by the presence of other socially important individuals that remained in the herd.

In E3 and E4, we observed behavioral changes that are more commonly associated with social stress. In E3 and E4, ruminating and eating times were reduced, respectively. Unlike the first 2 experiments, in E3 and E4 the groups were less fluid and the majority of group members were removed so that the remaining group members (e.g., E3, n = 9; E4, n =4) experienced a more similar situation to previous isolation studies where one or a small number of individuals are isolated from a larger group (von Keyserlingk et al., 2008). Consequently, remaining peers may not have been present in large enough numbers to effectively buffer the negative effect of separation, and previous experiences of separation may not have occurred with enough frequency to facilitate habituation. Following regrouping, calves housed in large groups (group size $\mathrm{n}=16$ ) have been shown to modify their behavior to indicate improved welfare, compared with calves housed in small groups (group size $n=4$; Færevik et al., 2007). Furthermore, in E3 feed intake was restricted by automated feeding equipment, which may explain why a reduction in rumination was observed and not feed intake.

The possibility that the behavioral observations in E3 and E4 were indicative of stress is supported by the approximately linear increase in $\operatorname{IgA}$ observed up to $6 \mathrm{~d}$ after separation. Although more research is required to confirm the comparative $\operatorname{Ig} \mathrm{A}$ concentrations in bovine milk versus serum, published research in other mammal species, including sows, dogs, and rats, has demonstrated that milk is rich in IgA (e.g., Heddle and Rowley, 1975; McGhee et al., 1975; Klobasa et al., 1987). One study by Näslund et al., (2000) demonstrated a high correlation between IgA titers in milk and serum, supporting the possibility of milk acting as a noninvasive alternative to serum. Additionally, IgA levels in milk appear to be consistent across lactational stages (Näslund et al., 2000). This suggests that it was the experimental design (group size and separation), rather than the substrate within which $\operatorname{Ig} \mathrm{A}$ was quantified, that was responsible for the observed (or lack of) changes in IgA after removal. Conversely, as we did not include a control in this study we cannot conclusively rule out the possibility that other variables (e.g., age, health status, or environmental changes) may account for the increase in IgA observed. To the authors' knowledge, all subjects were in healthy condition, had not recently received vaccination, and extreme weather changes did not occur during the course of the experiment nor any other notable stimuli that might have influenced IgA levels.

We also measured cortisol both between groups and before and after removal and found no significant changes, which may be because social separation is a chronic stressor. Cortisol has previously been used as a measure of the physiological effect (through HPA arousal) of social separation in a range of species and across a range of social relationships (Hennessy, 1997). These have predominately involved brief separations and have not always resulted in activation of the HPA system (Hennessy, 1997). As serum collection was obtained more than $12 \mathrm{~h}$ after removal in the present study, it is possible that HPA arousal had occurred but ended.

\section{CONCLUSIONS}

Behavioral responses to removal of predetermined individuals were observed in 4 experiments to be context specific. In 2 experiments with relatively large groups of dairy cows, social stress postseparation appears to have been diminished by social buffering or previous habituation to separation. In 2 experiments with smaller groups of cattle, IgA concentrations and nutritional responses suggest that social separation resulted in stress over several days. These responses suggest that social separation can be detrimental to the welfare of those remaining in the group but that the effect can be ameliorated by the presence of unstressed group members. 


\section{ACKNOWLEDGMENTS}

The authors thank Voiceless-The Animal Protection Institute (Sydney, Australia) and the European Social Fund DoRa Doctoral Studies and Internationalisation Programme (Estonia) for funding this research.

\section{REFERENCES}

Bøe, K. E., and G. Færevik. 2003. Grouping and social preferences in calves, heifers and cows. Appl. Anim. Behav. Sci. 80:175-190. http://dx.doi.org/10.1016/S0168-1591(02)00217-4.

Boissy, A., and H. W. Erhard. 2014. How studying interactions between animal emotions, cognition, and personality can contribute to improve farm animal welfare. Pages $81-113$ in Genetics and the Behavior of Domestic Animals. 2nd ed. T. Grandin and M. J. Deesing, ed. Academic Press, San Diego, CA.

Boissy, A., and P. Le Neindre. 1990. Social influences on the reactivity of heifers: Implications for learning abilities in operant conditioning. Appl. Anim. Behav. Sci. 25:149-165. http://dx.doi. org/10.1016/0168-1591(90)90077-Q.

Boissy, A., and P. Le Neindre. 1997. Behavioral, cardiac and cortisol responses to brief peer separation and reunion in cattle. Physiol. Behav. 61:693-699. http://dx.doi.org/10.1016/S00319384(96)00521-5.

Boissy, A., C. Terlouw, and P. Le Neindre. 1998. Presence of cues from stressed conspecifics increases reactivity to aversive events in cattle: Evidence for the existence of alarm substances in urine. Physiol. Behav. 63:489-495. http://dx.doi.org/10.1016/S00319384(97)00466-6.

Bouissou, M. F., A. Boissy, P. Le Neindre, and I. Veissier. 2001. The social behaviour of cattle. in Social Behaviour in Farm Animals. L. J. Keeling and H. Gonyou, ed. CABI, Wallingford, UK.

Broom, D. M. 2010. Cognitive ability and awareness in domestic animals and decisions about obligations to animals. Appl. Anim. Behav. Sci. 126:1-11. http://dx.doi.org/10.1016/j.applanim.2010.05.001.

Cooper, M. D., D. R. Arney, C. R. Webb, and C. J. C. Phillips. 2008. Interactions between housed dairy cows during feeding, lying, and standing. J. Vet. Behav. 3:218-227. http://dx.doi.org/10.1016/j. jveb.2007.09.005.

Dawkins, M. S. 1990. From an animal's point of view: Motivation, fitness, and animal welfare. Behav. Brain Sci. 13:1-9. http://dx.doi. org/10.1017/S0140525X00077104.

De Paula Vieira, A., M. A. G. von Keyserlingk, and D. M. Weary. 2010. Effects of pair versus single housing on performance and behavior of dairy calves before and after weaning from milk. J. Dairy Sci. 93:3079-3085. http://dx.doi.org/10.3168/jds.2009-2516.

Duncan, J. R., B. N. Wilkie, F. Hiestand, and A. J. Winter. 1972. The serum and secretory immunoglobulins of cattle: Characterization and quantitation. J. Immunol. 108:965-976.

Duve, L. R., D. M. Weary, U. Halekoh, and M. B. Jensen. 2012. The effects of social contact and milk allowance on responses to handling, play, and social behavior in young dairy calves. J. Dairy Sci. 95:6571-6581. http://dx.doi.org/10.3168/jds.2011-5170.

Færevik, G., I. L. Andersen, M. B. Jensen, and K. E. Bøe. 2007. Increased group size reduces conflicts and strengthens the preference for familiar group mates after regrouping of weaned dairy calves (Bos taurus). Appl. Anim. Behav. Sci. 108:215-228. http://dx.doi. org/10.1016/j.applanim.2007.01.010.

Færevik, G., M. B. Jensen, and K. E. Bøe. 2006. Dairy calves social preferences and the significance of a companion animal during separation from the group. Appl. Anim. Behav. Sci. 99:205-221. http://dx.doi.org/10.1016/j.applanim.2005.10.012.

Fogsgaard, K. K., C. M. Røntved, P. Sørensen, and M. S. Herskin. 2012. Sickness behavior in dairy cows during Escherichia coli mastitis. J. Dairy Sci. 95:630-638. http://dx.doi.org/10.3168/jds.20114350.
Fraser, D., and I. J. H. Duncan. 1998. 'Pleasures', 'pains' and animal welfare: Toward a natural history of affect. Anim. Welf. 7:383-396.

Fröberg, S., and L. Lidfors. 2009. Behaviour of dairy calves suckling the dam in a barn with automatic milking or being fed milk substitute from an automatic feeder in a group pen. Appl. Anim. Behav. Sci. 117:150-158. http://dx.doi.org/10.1016/j.applanim.2008.12.015.

Gibbons, J. M., A. B. Lawrence, and M. J. Haskell. 2010. Measuring sociability in dairy cows. Appl. Anim. Behav. Sci. 122:84-91. http://dx.doi.org/10.1016/j.applanim.2009.11.011.

Guhad, F. A., and J. Hau. 1996. Salivary IgA as a marker of social stress in rats. Neurosci. Lett. 216:137-140. http://dx.doi. org/10.1016/0304-3940(96)13037-8.

Hasegawa, N., A. Nishiwaki, K. Sugawara, and I. Ito. 1997. The effects of social exchange between two groups of lactating primiparous heifers on milk production, dominance order, behavior and adrenocortical response. Appl. Anim. Behav. Sci. 51:15-27. http://dx.doi. org/10.1016/S0168-1591(96)01082-9.

Heddle, R. J., and D. Rowley. 1975. Dog immunoglobulins. I. immunochemical characterization of dog serum, parotid saliva, colostrum, milk and small bowel fluid. Immunology 29:185-195.

Hennessy, M. B. 1997. Hypothalamic-Pituitary-Adrenal Responses to Brief Social Separation. Neurosci. Biobehav. Rev. 21:11-29. http://dx.doi.org/10.1016/S0149-7634(96)00013-9.

Holm, L., M. B. Jensen, and L. L. Jeppesen. 2002. Calves' motivation for access to two different types of social contact measured by operant conditioning. Appl. Anim. Behav. Sci. 79:175-194. http:// dx.doi.org/10.1016/S0168-1591(02)00137-5.

Honkanen-Buzalski, T., and M. Sandholm. 1981. Association of bovine secretory immunoglobulins with milk fat globule membranes. Comp. Immuno.l Microbiol. Infect. Dis. 4:329-342. http://dx.doi. org/10.1016/0147-9571(81)90019-9.

Kabuga, J. D. 1992. Social relationships in N'dama cattle during supplementary feeding. Appl. Anim. Behav. Sci. 34:285-290. http:// dx.doi.org/10.1016/S0168-1591(05)80089-9.

Keeling, L. J., and H. Gonyou. 2001. Social Behaviour in Farm Animals. CAB International, Wallingford, UK.

Kikkawa, A., Y. Uchida, T. Nakade, and K. Taguchi. 2003. Salivary secretory IgA concentrations in Beagle dogs. J. Vet. Med. Sci. 65:689-693.

Klobasa, F., E. Werhahn, and J. E. Butler. 1987. Composition of sow milk during lactation. J. Anim. Sci. 64:1458-1466. http://dx.doi. org/10.2134/jas1987.6451458x.

Krohn, C. C. 1994. Behaviour of dairy cows kept in extensive (loose housing/pasture) or intensive (tie stall) environments. III. Grooming, exploration and abnormal behaviour. Appl. Anim. Behav. Sci. 42:73-86. http://dx.doi.org/10.1016/0168-1591(94)90148-1.

Martin, P., and P. Bateson. 1993. Measuring Behaviour: An Introductory Guide, 2nd ed. Cambridge University Press, Cambridge, UK.

McGhee, J. R., S. M. Michalek, and V. K. Ghanta. 1975. Rat immunoglobulins in serum and secretions: Purification of rat IgM, IgA, and IgG and their quantitation in serum, colostrum, milk and saliva. Immunochemistry 12:817-823. http://dx.doi.org/10.1016/00192791(75)90146-9.

Mench, J. A., J. C. Swanson, and W. R. Stricklin. 1990. Social stress and dominance among group members after mixing beef cows. Can. J. Anim. Sci. 70:345-354. http://dx.doi.org/10.4141/cjas90046.

Mendl, M., and E. S. Paul. 2004. Consciousness, emotion and animal welfare: Insights from cognitive science. Anim. Welf. 13:17-25.

Miller, K., and D. G. M. Wood-Gush. 1991. Some effects of housing on the social behaviour of dairy cows. Anim. Sci. 53:271-278. http:// dx.doi.org/10.1017/S0003356100020262.

Mounier, L., I. Veissier, S. Andanson, E. Delval, and A. Boissy. 2006. Mixing at the beginning of fattening moderates social buffering in beef bulls. Appl. Anim. Behav. Sci. 96:185-200. http://dx.doi. org/10.1016/j.applanim.2005.06.015.

Näslund, K., M. Tråvén, B. Larsson, A. Silván, and N. Linde. 2000. Capture ELISA systems for the detection of bovine coronavirusspecific IgA and IgM antibodies in milk and serum. Vet. Microbiol. 72:183-206. http://dx.doi.org/10.1016/S0378-1135(99)00208-4. 
Newby, T. J., and J. Bourne. 1977. The nature of the local immune system of the bovine mammary gland. J. Immunol. 118:461-465.

Nicol, C. 2011. Behaviour as an indicator of animal welfare. Pages 31-68 in Management and Welfare of Farm Animals. J. Webster, ed. Wiley-Blackwell, Chichester, UK.

Rault, J. L. 2012. Friends with benefits: Social support and its relevance for farm animal welfare. Appl. Anim. Behav. Sci. 136:1-14. http://dx.doi.org/10.1016/j.applanim.2011.10.002.

Raussi, S., A. Boissy, E. Delval, P. Pradel, J. Kaihilahti, and I. Veissier 2005. Does repeated regrouping alter the social behaviour of heifers? Appl. Anim. Behav. Sci. 93:1-12. http://dx.doi.org/10.1016/j. applanim.2004.12.001.

Reinhardt, V., and A. Reinhardt. 1981. Cohesive relationships in a cattle herd (Bos indicus). Behaviour 77:121-150.

Royo, F., K. Lyberg, K. S. P. Abelson, H. E. Carlsson, and J. Hau. 2005. Effect of repeated confined single housing of young pigs on faecal excretion of cortisol and IgA. Scand. J. Lab. Anim. Sci $32: 33-37$.

Schirmann, K., N. Chapinal, D. M. Weary, W. Heuwieser, and M. A. G. von Keyserlingk. 2011. Short-term effects of regrouping on behavior of prepartum dairy cows. J. Dairy Sci. 94:2312-2319. http://dx.doi.org/10.3168/jds.2010-3639.

Segerstrom, S. C., and G. E. Miller. 2004. Psychological stress and the human immune system: A meta-analytic study of 30 years of inquiry. Psychol. Bull. 130:601-630.
Shutt, D. A., and L. R. Fell. 1985. Comparison of total and free cortisol in bovine serum and milk or colostrum. J. Dairy Sci. 68:1832-1834. http://dx.doi.org/10.3168/jds.S0022-0302(85)81035-3.

Skandakumar, S., G. Stodulski, and J. Hau. 1995. Salivary IgA: A possible stress marker in dogs. Anim. Welf. 4:339-350.

Snoeck, V., I. R. Peters, and E. Cox. 2006. The IgA system: A comparison of structure and function in different species. Vet. Res. 37:455-467. http://dx.doi.org/10.1051/vetres:2006010.

Spinka, M. 2012. Social dimension of emotions and its implication for animal welfare. Appl. Anim. Behav. Sci. 138:170-181. http:// dx.doi.org/10.1016/j.applanim.2012.02.005.

Veissier, I., and P. le Neindre. 1992. Reactivity of Aubrac heifers exposed to a novel environment alone or in groups of four. Appl. Anim. Behav. Sci. 33:11-15. http://dx.doi.org/10.1016/S01681591(05)80079-6.

von Keyserlingk, M. A. G., D. Olenick, and D. M. Weary. 2008. Acute behavioral effects of regrouping dairy cows. J. Dairy Sci. 91:10111016. http://dx.doi.org/10.3168/jds.2007-0532.

Walker, J., N. Waran, and C. J. C. Phillips. 2014. The effect of conspecific removal on the behaviour and physiology of pair-housed shelter dogs. Appl. Anim. Behav. Sci. 158:46-56. http://dx.doi. org/10.1016/j.applanim.2014.06.010. 